\title{
Bibliotherapy-based Wellness Program for Healthcare Providers: Using Books and Reading to Create a Healthy Workplace
}

\author{
Natalia Tukhareli ${ }^{1}$
}

\begin{abstract}
Within the context of benefits of a healthy workplace, bibliotherapy is seen as an effective way of promoting health and wellness to hospital employees. The paper will present a detailed description of an innovative informational and recreational bibliotherapy-based reading program for healthcare providers developed and implemented by a Health Sciences library, in collaboration with the Occupational Health department. The methodology involved an extensive review of the bibliotherapy research and best practices in the UK and North America. The mechanics, benefits, and challenges of the program will be discussed. The program evaluation included an internal survey to the hospital employees. The evaluation results show that the bibliotherapy program has provided a new venue to address work-related stress and promote health, well-being, and resilience within the organization. Moreover, it helped to expand opportunities for collaborative projects and partnerships for the library as well as increase visibility of the library within the organization.
\end{abstract}

\section{Introduction}

In the light of increased stress and work-related burnout of healthcare providers, employers strive to create and maintain the psychologically healthy workplace. Hospitals have been looking for effective ways to address psychological distress, job burnout, mental health, and compassion fatigue. Research shows that employer-sponsored wellness programs contribute to the overall health and well-being of their employees, improve employee productivity and retention, and reduce absenteeism and health care costs [1-2]. Studies explore various ways of promoting positive strategies for coping and building individual and organizational resilience, which are considered important factors that influence the health and productivity of healthcare workers [3-8]. Resilience is defined as "the process of effectively negotiating, adapting to, or managing significant sources of stress or trauma" [9]. As Robertson et al. [7] note, resilience is "increasingly necessary to maintain an effective, adaptive, and sustainable workforce." Jackson, Firtko and Edenborough [8] have identified effective resilience-building strategies, such as building positive and nurturing professional relationships, maintaining positivity, developing emotional insight, achieving life balance and spirituality, and becoming more reflective. Within this context, bibliotherapy is seen as an effective strategy of strengthening healthy thinking and resilience in healthcare providers.

"Bibliotherapy" is an umbrella term that covers a wide variety of clinical (therapeutic) and non-clinical (developmental, creative, social) interventions involving books, reading, and communication around texts. In the broadest sense of the term, bibliotherapy is the systematic use of books to assist individuals in dealing with mental, physical, emotional, developmental, or social problems [10]. It has been also widely recognized as an effective tool of promoting health, well-being, and resilience, which reflects the view of literature as "being healthpromoting in the widest human sense" [11]. Today, bibliotherapy offers a variety of successful applications that range from one-on-one and group

Natalia Tukhareli. Librarian, Health Sciences Library, Scarborough and Rouge Hospital, Scarborough ON

${ }^{1}$ Corresponding author (email: ntukhareli@rougevalley.ca)

This article has been peer-reviewed.

(c) Tukhareli.

This article is distributed under a Creative Commons Attribution License: https://creativecommons.org/licenses/by/4.0/ 
sessions run by psychologists and psychiatrists in medical clinics and hospitals [12-13], to collaborative "Books on Prescription" programs offered by public libraries partnering with healthcare organizations [1415], to "shared reading" groups facilitated in a variety of settings, including libraries, schools, retirement homes, hospitals, drug rehabilitation units, shelters, community centers, and prisons [11, 16-17].

Literature, in a variety of its genres, can provide a broad variety of fictional and non-fictional accounts that individuals face in their lives, both at work and at home. While exploring these stories from a safe distance, readers have always a chance to reflect on their personal situations and get insight into life's challenges. Given that, it has been suggested that the integration of books and reading into a workplace wellness program can expand the 'therapeutic' space for reflection and emotional insight for the hospital employees as well as educate them on evidence-based strategies of managing occupational stress and enhancing personal well-being and resilience. This assumption is supported by the findings of the author's previous review of the scholarly research and best practices in bibliotherapy [10] as well as the recent analysis of the research studies exploring the potential of bibliotherapy-based interventions in addressing workplace health and well-being [18-22]. The paper will present a detailed description of an innovative, informational, and recreational reading program for healthcare providers developed and implemented by a librarian from the Health Sciences Library, in collaboration with the Occupational Health department at Scarborough and Rouge Hospital (formerly Rouge Valley Health System, a medium-sized community hospital in the Greater Toronto Area in Ontario). It involves thematic compilations of readings for the hospital employees to promote a healthy workplace. The targeted population included both clinical and non-clinical groups, including nurses, physicians, allied health professionals, the hospital administration, the management, volunteers, etc. The hospital patients have not participated in the program.

\section{Program Description}

The "Bibliotherapy for Staff" program provides an example of an innovative application of bibliotherapy in a medical library setting. The conceptual idea was developed by the author in 2011. After reviewing principal features, delivery methods, and benefits and limitations of existing clinical and non-clinical bibliotherapy-based programs in the UK and North America, the author suggested a new way of using books and reading to promote individual and community health, well-being, and resilience. The approach involves addressing existential, or "living problems," through thematic compilations of readings of various genres. It was initially featured in the program "Read to Connect" that the author developed for the clients of St. John the Compassionate Mission, a non-profit organization supporting disadvantaged community members in Toronto, ON. The program participants included individuals coping with difficult transitions and challenges in their lives, such as homelessness, relocation, loss and bereavement, family issues, and parenting challenges. Delivered in 2011-2012, the program involved reading and communication around texts in small groups. The author identified specific themes relevant to the targeted client group and developed compilations of fictional and non-fictional reading materials to address these themes. The topics addressed throughout the program included "loneliness," "dealing with adversity," "loss and grief," "forgiveness," "gratitude," "positive attitude," "meaning in life," "compassion," "love and giving," "self-acceptance," "responsibility," "parenting," and more. The innovative content of the "Read to Connect" program was delivered within a "shared reading" model (a read-aloud session in a group setting) developed by the Reader organization in the UK [17]. The "Bibliotherapy for Staff" program described in this paper presents a modified version of the author's original program adjusted to a new client group.

The idea was first introduced to the staff of the Rouge Valley Health System (RVHS) in December 2014, when the author, the librarian at the Health Sciences Library, put together a compilation of reading materials (excerpts from fictional and nonfictional texts and poems) to address the holiday stress. The compilation received a good feedback from the hospital staff including the senior management team. During consultations with the Occupational Health department in January 2015, it has been suggested that the program may provide a new venue to address wellness and healthy workplace themes at the RVHS. The Occupational Health Manager has suggested the first two topics to be addressed through the library program, such as healthy living and resilience. This put a start for the "Bibliotherapy for Staff" program, 
an innovative bibliotherapy-based informational and recreational library program.

When introducing and promoting the new library service within the organization, we identified the program objectives. It was suggested that the program will

- provide an additional venue to address wellness and healthy workplace topics within the organization;

- contribute to improved health and well-being of the hospital staff by promoting healthy lifestyle, healthy thinking, and resilience;

- educate staff on new approaches in stress management (positive psychology interventions, mindfulness techniques, music therapy, horticultural therapy, etc.);

- expand opportunities for collaborative projects and partnerships for the library;

- increase visibility of the library within the organization and traffic on the library's website.

Since the launch of the program, we have developed twelve compilations of readings covering a variety of health and wellness topics, such as healthy living, positive thinking, gratitude, resilience, lifework balance, meaning and purpose in life, change management, and more. The reading materials were selected from a broad variety of both fiction and nonfiction texts, including parables, short stories, novels, poetry, biographies, autobiographies, self-help books and websites, academic manuscripts, and research articles in the health sciences, humanities, and social sciences. It has been suggested that while fictional materials and poetry would provide a chance for reflection and observation, non-fiction materials would educate staff on resilience-building strategies supported by recent developments in the fields of positive psychology, neuroplasticity, and complimentary therapies. Each compilation included a brief introduction with the librarian's personal reflections on the topic. The length of the compilations varied between 4 and 8 pages.

Specific criteria for selecting materials included relevance of materials to the topics addressed, high literary quality of fiction and poetry, and a strong evidence-based support for non-fictional materials. We have ensured the high quality of reading materials by selecting fiction and poetry by prominent classical and contemporary authors, such as Charles Dickens, Paul Bowles, Paolo Coelho, Antoine De Saint-Exupery,
Ernest Hemingway, Alistair MacLeod, Alice Munro, Rainer Maria Rilke, Emily Dickinson, Mary Oliver, etc. When selecting non-fictional materials (e.g. works in psychology, philosophy, the environmental science, neuroscience, etc.), we would consider the author's expertise in a particular filed. The compilations included excerpts from groundbreaking works by Victor Frankl, Erich Fromm, Dalai Lama, David Suzuki, Jean Vanier, Elizabeth Kübler-Ross, Norman Doidge, and other renowned authors in different fields of the humanities, social sciences, and health sciences.

It should be also mentioned that taking into account the workplace diversity at RVHS, we aimed at selecting materials that would speak to individuals representing different cultural and spiritual traditions. The following materials included into the "Healing Garden" compilation show the variety and diversity of the program content: poems by Emily Dickinson, Chief Dan George, and Japanese haikus; excerpts from the novel "The Old Man and the Sea," by Ernest Hemingway; excerpts from the environmental works by David Suzuki and Thomas Berry; excerpts from writings by Dalai Lama; and abstracts from research studies on horticultural therapy and nature-based rehabilitation, including recent studies of Shinrin-yoku ("forest bathing").

When selecting specific materials for thematic compilations, the librarian ensured that the use of materials stayed within the boundaries of fair dealing in Canadian copyright law or sought permission from copyright holders. The amount to be used was determined using the organization's fair dealing guidelines around what is considered a short excerpt for non-commercial use for the purpose of education. In cases where selections included copyrighted materials published on institutional websites, the librarian submitted formal requests and was granted permission to use specific materials for the purpose of the reading program. Some works in the public domain were also used, and proper citations were provided for all materials.

We used different delivery methods to distribute the compilations of readings to the hospital staff. These included a weekly hospital electronic newsletter (a direct link to a PDF file); a web page on the Library Intranet; displays with print copies of compilations in the Library and the Occupational Health department; and print copies added to the Library's training packages for staff. In addition, the Manager of the Occupational Health department would send 
customized emails to specific clinical groups and the management.

\section{Outcomes}

The program evaluation included an internal survey to the hospital employees, which was open for a period of 8 weeks (March-April 2016). The survey was distributed online through the Library's web page, group emails, and the hospital electronic newsletter. Print copies of the survey were displayed in the library. The staff was asked to share their feedback on past compilations of readings as well as suggest ideas for future topics that could be addressed through the program; please see Appendix for a complete list of the survey questions.

Overall, a small sample of 32 responses was received. However, the participants of the survey represented both clinical and non-clinical groups in the hospital, including nurses, physicians, Human Resources, Health Records, Occupational Health, and the management.

We were particularly interested in the participants' input in regards to the following statements: "Readings contributed to improved well-being (provided relaxation and/or reduced stress)" and "Readings provided insights or a new perspective on my current situation in life and/or at work." $81.3 \%$ $(n=26)$ of respondents rated both statements between 7 and 10 (on the scale from 1 to 10 , with 10 being the highest). Respondents have also expressed their overall satisfaction with the variety and quality of materials selected $(87.5 \%, \mathrm{n}=28)$ and the length of compilations $(84.4 \%, n=27)$. It should be also noted that one of the first respondents to the survey, the physician affiliated with the RVHS, asked to add the listserv option under delivery methods. He wrote, "Have a mailing list so that those who are genuinely interested, as I am, can be assured of receiving the publication regularly." After we added this option, 15 people have provided their email addresses.

We also received 23 comments from the survey participants. Respondents have suggested specific topics to be addressed in the future: 1) "learning to slow down in the present "crazy-pace" life"; "the value of solitude"; 2) "care of the elderly (parents), care of seriously ill or injured children"; 3) "bullying (being bullied in the workplace by coworkers)"; 4) "fear/uncertainty/anxiety of the unknown at work and in life"; and 5) "love for what one is doing." Two participants suggested including "more real stories about healthcare workers' experiences" and "stories related to working in a healthcare environment" into compilations.

The testimonies below reflect the participants' appreciation of the library's program:

"A truly relatable and meaningful grouping of compilations that have impacted me far more than I ever could have realized. I am grateful for how they encourage me to dig deep within myself and allow myself to feel and understand things that I've otherwise pushed aside either consciously or unconsciously."

"I never thought about how useful this could be in my life and work. Thank you for bringing it to the forefront."

"Thanks very much!! I enjoyed the readings and found them to be insightful and relaxing. A great way to escape during a hectic and busy day."

Overall, the survey data showed that the topics addressed through thematic compilations of readings were relevant to the needs of healthcare providers and non-clinical staff. The "Bibliotherapy for Staff" program was viewed as a valuable stress-management intervention and an effective strategy to improve individual and organizational resilience.

\section{Discussion}

Within the context of traditional workplace wellness programs and services, this informational and recreational library program has provided a new venue to address workplace wellness and promote healthy lifestyle to hospital employees. The thematic compilations of readings facilitated reflection on core existential themes (i.e. adversity, loss, forgiveness, gratitude, purpose in life) and more specific workrelated issues (life-work balance, meaningful work, work stress), thus providing individuals with an opportunity to get insight into their own situations in life and at work. The readings also educated staff on new approaches in stress management that can help activate one's personal resources, strengthen healthy thinking and positive professional relationships, and develop an individual strategy to respond on work pressures and constant change. The informational component of reading compilations, with its focus on healthy living tools and resilience-building strategies supported by research findings in positive psychology and neuroplasticity, has been considered an important 
factor of the program's success. The program participants have acknowledged high quality of selfhelp resources on "healthy lifestyle" (eating, exercise, outdoor activities, community engagement) and "healthy thinking" (positive psychology and mindfulness techniques) into reading compilations.

From the library's perspective, the program proved to be a simple, cost-effective, and easy to implement library service. The only barrier identified during the implementation of the program was the librarian's time. Selection of materials is a time-consuming task, which involves extensive searching, reading, critical evaluation of the quality of materials (particularly selfhelp books), as well as a creative process of compiling readings under a certain theme. The average time required to develop and administer one monthly compilation was 16 hours (4 hours per week). It became obvious that monthly compilations were not sustainable given the rest of the librarian's workload. As a result, the program delivery frequency has been adjusted from monthly to quarterly.

Another question addressed at the early stage of the program's implementation was around the skills needed to facilitate the initiative. Librarians do have proper skills and qualifications to develop and run the program, including literary knowledge and expertise, literature search skills, and the ability to find trustworthy information sources and critically evaluate information. In this particular case, the librarian's previous experience delivering bibliotherapy-based reading programs and thorough knowledge of the classical and contemporary literature were considered important assets. Also, due to the collaborative nature of the program, the librarian had an opportunity to discuss the relevance of the proposed themes for reading compilations and selected materials with the staff of the Occupational Health department and get the final approval from the department's manager.

From a library marketing perspective, the program has significantly increased the visibility and the perceived value of the library within the hospital and outside the organization. In 2016, the RVHS was named one of the GTA's Top employers. In the Memorandum circulated to the hospital employees, bibliotherapy service was listed among other workplace wellness initiatives contributed to the award: "providing a healthy workplace series of seminars and supports, as well as offering bibliotherapy (a systematic use of reading materials to help people cope with mental, physical, emotional, developmental or social problems)" [23].
The success of the program led to other new collaborative projects for the library. For example, compilations on healthy thinking and gratitude were expanded into an Interdisciplinary Lunch \& Learn session "Benefits of positive thinking: How to improve health and well-being through fostering optimism and gratitude" co-facilitated by the Librarian and the Ability Case Management Specialist. This session was repeated three times for specific hospital groups, including human resources, operating room staff, and the nursing department. Moreover, the possible expansion of the reading program into group workshops with clinicians to address compassion fatigue and stress has been discussed.

In conclusion, the "Bibliotherapy for Staff" program shows a creative way of integrating books and reading into library services to promote health, well-being, resilience, and personal growth at workplace. Overall, the program has demonstrated the value of books and communication around texts in addressing workplace wellness within a hospital environment. This suggests that creative bibliotherapy can be further explored within the context of traditional support services offered in the workplace. Librarians are encouraged to develop similar collaborative initiatives at their organizations as well as look for new ways of applying books and reading into everyday life.

\section{Statement of Competing Interests}

No competing interests declared.

\section{References}

1. Kaspin LC, Gorman KM, Miller RM. Systematic review of employer-sponsored wellness strategies and their economic and health-related outcomes. Popul Health Manag. 2013 Feb; 16(1): 14-21. doi: 10.1089/pop.2012.0006.

2. Soldano SK. Workplace wellness programs to promote cancer prevention. Semin Oncol Nurs. 2016 Aug; 32(3): 281-90. doi: 10.1016/j.soncn.2016.05.008.

3. Pipe TB, Buchda VL, Launder S et al. Building personal and professional resources of resilience and agility in the healthcare workplace. Stress Health. 2012 Feb; 28(1):11-22. doi: 10.1002/smi.1396. 
4. Johnson JR, Emmons HC, Rivard RL, Griffin KH, Dusek JA. Resilience training: a pilot study of mindfulness-based program with depressed healthcare professionals. Explore (NY). 2015 Nov-Dec; 11(6):433-44. doi: 10.1016/j.explore.2015.08.002.

5. Mallak LA, Yildiz M. Developing a workplace resilience instrument. Work. 2016 May 27; 54(2):241-53. doi: 10.3233/WOR-162297.

6. Mealer M, Conrad D, Evans J et al. Feasibility and acceptability of a resilience training program for intensive care unit nurses. Am J Crit Care. 2014 Nov; 23(6):e97-105. doi: 10.4037/ajcc2014747.

7. Robertson HD, Elliott AM, Burton C et al. Resilience of primary healthcare professionals: a systematic review. Br J Gen Pract. 2016 Jun; 66(647): e423-33. doi: 10.3399/bjgp16X685261.

8. Jackson D, Firtko A, Edenborough M. Personal resilience as a strategy for surviving and thriving in the face of workplace adversity: a literature review. J Adv Nurs. 2007 Oct; 60(1):1-9. doi: 10.1111/j.1365-2648.2007.04412.x.

9. Windle G. What is resilience? A review and concept analysis. Rev Clin Gerontol. 2010; 21(2): 152-169. doi: 10.1017/S0959259810000420.

10. Tukhareli N. Healing through books: the evolution and diversification of bibliotherapy. Edwin Mellen Press; 2014. 206 p.

11. Dowrick C, Billington J, Robinson J, Hamer A, Williams C. Get into reading as an intervention for common mental health problems: Exploring catalysts for change. Med Humanit. 2012 Jun; 38(1): 15-20. doi: 10.1136/medhum-2011-010083.

12. Mendel MR, Harris J, Carson N. Bringing bibliotherapy for children to clinical practice. $\mathrm{J}$ Am Acad Child Adolesc Psychiatry. 2016 July; 55(7):535-7. doi: 10.1016/j.jaac.2016.05.008.

13. Volpe U, Torre F, De Santis V, Perris F, Catapano F. Reading group rehabilitation for patients with psychosis: a randomized controlled study. Clin Psychol Psychother. 2015 Jan-Feb; 22:15-21. doi: 10.1002/cpp.1867.

14. Robertson R, Wray S J, Maxwell M, Pratt RJ. The introduction of a healthy reading scheme for people with mental health problems: usage and experiences of health professionals and library staff. Ment Health Fam Med. 2008 Dec; 5:219-228.
15. Carty S, Thompson L, Berger S, Jahnke K, Llewellyn R. Books on prescription - communitybased health initiative to increase access to mental health treatment: an evaluation. Aust N Z J Public Health. 2016 Jun; 40(3):276-8. doi: 10.1111/17536405.12507.

16. Hodge S, Robinson J, Davis P. Reading between the lines: The experiences of taking part in a community reading project. J Med Ethics. 2007 Dec: 33:100-4. doi: 10.1136/jmh.2006.000256.

17. Davis J. Enjoying and enduring: groups reading aloud for wellbeing. Lancet. 2009 Feb; 373 (9665):714-5.

18. Mårtensson L, Andersson C. Reading fiction during sick leave, a multidimensional occupation. Scand J Occup Ther. 2015 Jan; 22 (1): 62-71. doi: 10.3109/11038128.2014.955877.

19. Kilfedder C, Power K, Karatzias T et al. A randomized trial of face-to-face counselling versus telephone counselling versus bibliotherapy for occupational stress. Psychol Psychother. 2010 Sep; 83(Pt 3):223-42. doi: $10.1348 / 147608309 \times 476348$.

20. Jeffcoat T, Hayes SC. A randomized trial of ACT bibliotherapy on the mental health of K-12 teachers and staff. Behav Res Ther. 2012 Sep; 50(9):571-9. doi: 10.1016/j.brat.2012.05.008.

21. Sharma V, Sood A, Prasad K, Loehrer L, Schroeder D, Brent B. Bibliotherapy to decrease stress and anxiety and increase resilience and mindfulness: a pilot study. Explore (NY). 2014 Jul-Aug; 10(4):248-52. doi: 10.1016/j.explore.2014.04.002.

22. Songprakun W, McCann TV. Using bibliotherapy to assist people to recover from depression in Thailand: Relationship between resilience, depression and psychological distress. Int J Nurs Pract. 2015 Dec; 21(6):716-24. doi: 10.1111/ijn.12250.

23. Rouge Valley Health System [Internet]. Scarborough: Rouge Valley Health System; c2017. Rouge Valley named one of Greater Toronto Area's top employers; 2015 Dec 15 [cited 2017 Jun 20]; Available from: http://www.rougevalley.ca/rouge-valley-namedone-of-greater-toronto-area-s-top-employers 


\section{Appendix: Evaluation Survey Form}

Your feedback is important to us!

Thank you for participating in the evaluation of "Bibliotherapy for Staff" library program. Please take a moment to tell us what you thought of the published compilations of 'therapeutic readings' and your ideas for future topics.

\begin{tabular}{|c|c|c|}
\hline 1. & \multicolumn{2}{|l|}{$\begin{array}{l}\text { Name (optional): } \\
\text { Title or Department: }\end{array}$} \\
\hline \multirow[t]{7}{*}{2.} & $\begin{array}{l}\text { Please rate your agreement with each of the following statements } \\
\text { on a scale from } 1-10 \text {, with } 10 \text { being the highest: }\end{array}$ & Rating \\
\hline & Topics addressed were relevant to my informational and recreational needs. & \\
\hline & $\begin{array}{l}\text { Readings contributed to improved well-being (provided relaxation and/or } \\
\text { reduced stress). }\end{array}$ & \\
\hline & $\begin{array}{l}\text { Readings provided insights or a new perspective on my current situation in life } \\
\text { and/or at work. }\end{array}$ & \\
\hline & I like the variety and quality of materials selected. & \\
\hline & I find the length of published compilations appropriate. & \\
\hline & Delivery methods (e-Echo; Library website; Library displays) are effective. & \\
\hline 3. & What additional topics would you like to be addressed? & \\
\hline 4. & Please provide your e-mail address if you would like to receive our future comp & s by e-mail. \\
\hline 5 . & Are any other comments or thoughts that you would like to share? & \\
\hline
\end{tabular}

Thank you for your valuable time and input! 